\title{
Type 2 diabetes alters bone and marrow blood flow and vascular control mechanisms in the ZDF rat
}

\author{
John N Stabley ${ }^{1}$, Rhonda D Prisby ${ }^{2}$, Bradley J Behnke ${ }^{1,3}$ and Michael D Delp ${ }^{1,4}$ \\ ${ }^{1}$ Department of Applied Physiology and Kinesiology, University of Florida, Gainesville, Florida 32611, USA \\ ${ }^{2}$ Department of Kinesiology and Applied Physiology, University of Delaware, Newark, Delaware 19713, USA \\ ${ }^{3}$ Department of Kinesiology, Kansas State University, Manhattan, Kansas 66506, USA \\ ${ }^{4}$ Department of Nutrition, Food and Exercise Science, College of Human Sciences, Florida State University, \\ 242 Sandels Building, 120 Convocation Way, Tallahassee, Florida 32306, USA
}

Correspondence should be addressed to M D Delp

Email

mdelp@fsu.edu

\begin{abstract}
Bone health and cardiovascular function are compromised in individuals with type 2 diabetes mellitus (T2DM). The purpose of this study was to determine whether skeletal vascular control mechanisms are altered during the progression of T2DM in Zucker diabetic fatty (ZDF) rats. Responses of the principal nutrient artery (PNA) of the femur from obese ZDF rats with prediabetes, short-term diabetes, and long-term diabetes to endotheliumdependent (acetylcholine) and -independent (sodium nitroprusside) vasodilation and potassium chloride, norepinephrine (NE), and a myogenic vasoconstrictor were determined in vitro. Few changes in the PNA vasomotor responses occurred for the prediabetic and short-term diabetic conditions. Endothelium-dependent and -independent vasodilation were reduced, and NE and myogenic vasoconstriction were increased in obese ZDF rats with long-term diabetes relative to lean age-matched controls. Differences in endotheliumdependent vasodilation of the femoral PNA between ZDF rats and controls were abolished by the nitric oxide synthase inhibitor $N^{G}$-nitro-L-arginine methyl ester. The passive pressurediameter response of the femoral PNA was also lower across a range of intraluminal pressures with long-term T2DM. Regional bone and marrow perfusion and vascular conductance, measured in vivo using radiolabeled microspheres, were lower in obese ZDF rats with long-term diabetes. These findings indicate that the profound impairment of the bone circulation may contribute to the osteopenia found to occur in long bones during chronic T2DM.
\end{abstract}
Key Words
$\checkmark$ diabetes
bone blood flow
- endothelium
- vascular conductance
- Zucker diabetic fatty rat

\section{Introduction}

The increase in fracture risk observed among patients with type 2 diabetes mellitus (T2DM) has been suggested to be associated with corollaries of the disease, such as peripheral neuropathy, decreased physical fitness, vision loss, and poor balance (Schwartz 2003, Melton et al. 2008, http://joe.endocrinology-journals.org DOI: 10.1530/JOE-14-0514
() 2015 Society for Endocrinology Printed in Great Britain
Leslie et al. 2012). Emerging results also indicates a causal link between cardiovascular function and indices of bone health (Parfitt 2000, Farhat \& Cauley 2008, Lampropoulos et al. 2012, Prisby et al. 2012). Cardiovascular disease is a leading complication of T2DM (Grundy et al. 1999), 
including impairment of endothelium-dependent vasodilation of large conduit arteries (Hogikyan et al. 1998, Makimattila et al. 1999, van de Ree et al. 2001, Rossi et al. 2005).

Previous findings obtained using obese Zucker diabetic fatty (ZDF) rats (Lesniewski et al. 2008), an animal model of T2DM, indicate that an impairment of endothelium-dependent vasodilation through the nitric oxide (NO) signaling mechanism effectively changes the balance of vasomotor control in skeletal muscle arterioles to favor vasoconstriction. Decreases in bone mineral density (BMD) have also been shown to occur in obese ZDF rats with long-term T2DM (Prisby et al. 2008) and is one basis for the decrease in mechanical strength of long bones in the hindlimb. It has been proposed that one contributing factor to this decrease in BMD and mechanical strength could be a reduction in bone and marrow blood flow and impairment of coupling mechanisms linking endothelium-dependent vasodilation to bone cell remodeling activity (Prisby et al. 2008). For example, reduced blood flow to the bone and marrow of the femur occurs in aged rats (Prisby et al. 2007), and this is accompanied by an impairment of the ability of the femoral principal nutrient artery (PNA) to vasodilate by way of a NO signaling mechanism (Prisby et al. 2007). In addition, results of previous experiments with young and old exercise-trained rats (Dominguez et al. 2010) and ovariectomized rats (Prisby et al. 2012) indicate a coupling of endotheliumdependent vasodilation to measures of bone volume. Therefore, the purpose of this study was to determine whether control mechanisms of the skeletal resistance vasculature, including endothelium-dependent vasodilation, are altered during the progression of T2DM when BMD is both increasing and decreasing (Prisby et al. 2008). We proposed that endothelium-dependent vasodilation of the femoral PNA would be higher in prediabetic 7-weekold obese ZDF rats when femoral BMD is greater than that in 7-week-old lean ZDF rats, and that endotheliumdependent vasodilation would be impaired in long-term diabetic 20-week-old obese ZDF rats when femoral BMD is reduced. Results from these vascular studies indicated that endothelium-dependent vasodilation of the PNA was diminished with long-term diabetes, along with other vascular mechanisms that serve to regulate bone perfusion. Consequently, a secondary purpose of this study was to determine the effects of frank T2DM on hindlimb bone and marrow blood flow and vascular conductance. We proposed that bone and marrow perfusion would be lower in animals with long-term diabetes relative to that in 20-week-old lean ZDF animals.

\section{Materials and methods}

\section{Animals}

All experimental procedures were approved by the University of Florida's Institutional Animal Care and Use Committee and conformed to the National Institutes of Health Guide for the Care and Use of Laboratory Animals (Eighth edition, 2011). Lean (371:+/?) and obese (370: $\mathrm{Fa} / \mathrm{Fa}$ ) ZDF rats were obtained from Charles River Laboratories (Kingston, NY, USA). Obese ZDF rats are homozygous for the fatty $(\mathrm{Fa})$ gene (Truett et al. 1991) and when fed the Purina 5008 diet they manifest obesity and hyperlipidemia (Leonard et al. 2005). Seven-week-old obese ZDF rats manifest hyperinsulinemia and mild hyperglycemia and have been classified as prediabetic. The strain develops more severe hyperglycemia by 13 weeks of age (short-term diabetes) and becomes normo- or hypoinsulinemic by 20 weeks of age (long-term diabetes) (Peterson et al. 1990, Etgen \& Oldham 2000). Animals used in this study were provided Purina 5008 diet and water and allowed to eat and drink ad libitum maintained on a $12 \mathrm{~h}$ light: $12 \mathrm{~h}$ darkness cycle, and studied at 7 weeks (lean, $n=28$; obese, $n=29$ ), 13 weeks (lean, $n=28$; obese, $n=28$ ), and 20 weeks (lean, $n=51$; obese, $n=51$ ) of age to correspond to the prediabetic, short-term diabetic, and long-term diabetic states in the obese ZDF rats respectively.

\section{Isolated microvessels}

Animals were anesthetized with isoflurane $\left(2 \% / \mathrm{O}_{2}\right.$ balance), a thoracotomy was performed, and $2 \mathrm{ml}$ of blood was withdrawn via cardiac puncture before excision of the heart. Immediately after killing, the hindlimbs were removed and placed into a dissecting bath containing $4{ }^{\circ} \mathrm{C}$ physiological saline solution (PSS). Femoral PNAs, which regulate approximately $70 \%$ of the blood supply to the femoral bone marrow and cortex (Bridgeman \& Brookes 1996), were isolated, cannulated, and pressurized with PSS at $60 \mathrm{~cm} \mathrm{H}_{2} \mathrm{O}(44 \mathrm{mmHg})$ as described previously (Prisby et al. 2007, Dominguez et al. 2010). This pressure was selected on the basis of intravascular arterial pressures measured within similar sized skeletal muscle resistance arteries of 43-46 mmHg (Meininger et al. 1984).

\section{Experimental design}

Endothelium-dependent vasodilation of femoral PNAs ( $n=14-15 /$ group) was assessed by the cumulative addition of acetylcholine (ACh, $\left.10^{-9}-10^{-4} \mathrm{~mol} / \mathrm{l}\right)$. To determine

Published by Bioscientifica Ltd. 
the contribution of the NO signaling pathway to endothelium-dependent vasodilation, PNAs were incubated with the NO synthase (NOS) inhibitor $N^{\mathrm{G}}$-nitro-L-arginine methyl ester (L-NAME, $10^{-5} \mathrm{~mol} / \mathrm{l}$ ) (Muller-Delp et al. 2002, Prisby et al. 2007, Dominguez et al. 2010), and the ACh dose-response was repeated. To investigate the contribution of prostaglandin signaling to endotheliumdependent vasodilation, PNAs were co-incubated with L-NAME and the cyclooxygenase (COX) inhibitor indomethacin $\left(10^{-5} \mathrm{~mol} / \mathrm{l}\right)$ (Prisby et al. 2007), and the ACh dose-response was repeated. Endotheliumindependent vasodilator responsiveness was assessed via the cumulative addition of the NO donor sodium nitroprussside (SNP, $10^{-9}-10^{-4} \mathrm{~mol} / \mathrm{l}$ ). Lastly, maximal intraluminal diameter and medial wall thickness were determined after two 15-min incubations in $\mathrm{Ca}^{2+}$-free PSS supplemented with SNP $\left(10^{-4} \mathrm{~mol} / \mathrm{l}\right)$ to achieve complete smooth muscle relaxation. Medial wall thickness was recorded as the average of three distinct wall measurements made with a video caliper as previously described (Stabley et al. 2013).

Using a separate set of rats ( $n=13-14$ /group), vasoconstrictor responses of PNAs to increasing concentrations of potassium chloride $(\mathrm{KCl}, 10-100 \mathrm{mmol} / \mathrm{l})$ were determined to investigate the contribution of voltage-gated $\mathrm{Ca}^{2+}$ channels. Concentrations of $\mathrm{NaCl}$ and $\mathrm{KCl}$ in PSS were balanced such that bath osmolarity was maintained and the desired isotonic $\mathrm{K}^{+}$bath concentrations were achieved (Donato et al. 2005). Vasoconstrictor responses to the cumulative addition of norepinephrine (NE, $\left.10^{-9}-10^{-4} \mathrm{~mol} / \mathrm{l}\right)$ were recorded to measure the contribution of $\alpha$ adrenoreceptors (Delp 1999). In a separate group of 20-week-old animals (lean, $n=11$; obese, $n=10$ ), the endothelium of PNAs was removed by passing 3-5 ml of air through the lumen as described previously (Donato et al. 2005). Administration of a bolus dose of ACh $\left(10^{-5} \mathrm{~mol} / \mathrm{l}\right)$ was used to confirm the successful removal of the endothelium, and measurement of the PNA response to the cumulative addition of $\mathrm{NE}$ was determined.

Active myogenic responses to stepwise increases in intraluminal pressure were determined by raising the height of both fluid reservoirs in $15 \mathrm{~cm} \mathrm{H}_{2} \mathrm{O}$ increments from 0 to $135 \mathrm{~cm} \mathrm{H}_{2} \mathrm{O}$. Intraluminal pressure was then decreased in $15 \mathrm{~cm} \mathrm{H}_{2} \mathrm{O}$ decrements back to $0 \mathrm{~cm} \mathrm{H}_{2} \mathrm{O}$. Passive myogenic responses to stepwise increases in intraluminal diameter were determined using the steps employed for the active myogenic response described above except that the vessel bathing solution was replaced with $\mathrm{Ca}^{2+}$-free PSS plus SNP $\left(10^{-4} \mathrm{~mol} / \mathrm{l}\right)$ as described previously (Delp 1999).

\section{Peripheral quantitative computed tomography}

Tomographic scans were performed ex vivo on femoral mid-shafts and distal femora in PBS using a Stratec XCT Research-M device as reported previously (Prisby et al. 2008). Reported measurements of cortical BMD were derived from the femoral mid-shaft and reported measurements of total and cancellous BMD were derived from the distal femora. For precision of the measurements, calibration of the Stratec XCT Research-M device was performed before scanning by use of a hydroxyapatite standard cone phantom. The distal metaphysis of the femur was scanned 4,5 , and $6 \mathrm{~mm}$ from the proximal plateau and the mid-diaphysis was scanned (on center) $8 \mathrm{~mm}$ from the distal end of the lateral epicondyles. For both the distal metaphysis and mid-diaphysis, values from multiple slices were averaged. Scans were performed at $5 \mathrm{~mm} / \mathrm{s}$ with voxel resolution of $0.07 \times 0.07 \times 0.5 \mathrm{~mm}$. In addition, analyses were performed using cut and peel modes of 3 and 2. According to the manufacturer's data, machine precision is $\pm 3.0 \mathrm{mg} / \mathrm{cm}^{3}$ for cancellous bone and $\pm 9.0 \mathrm{mg} / \mathrm{cm}^{3}$ for cortical bone.

\section{Surgical procedures}

Blood flow was measured using a separate group of 20 -week-old lean $(n=12)$ and obese $(n=12)$ ZDF rats as described previously (Colleran et al. 2000, Prisby et al. 2007). The animals were anesthetized with isoflourane (2-2.5\%/ $\mathrm{O}_{2}$ balance) and a polyethylene catheter filled with heparinized saline solution $(100 \mathrm{U} / \mathrm{ml})$ was implanted in the ascending aorta via the right carotid artery. Blood (approximately $300 \mu \mathrm{l}$ ) was collected from this catheter to determine plasma insulin and glucose concentrations. A separate polyethylene catheter was implanted into the caudal artery of the tail for withdrawal of reference blood samples (Delp \& Armstrong 1988). Each animal was allowed a minimum of $3 \mathrm{~h}$ of recovery after wound closure and the cessation of anesthesia before experiments to measure tissue blood flow were performed. Results of previous research indicate that cardiovascular dynamics, regional blood flow, and acid-base status recover to normal levels within $3 \mathrm{~h}$ after anesthesia (Flaim \& Zelis 1980).

\section{Determination of blood flow}

Bone blood flow was measured using radiolabeled microspheres while the animals with long-term diabetes and 20-week-old age-matched lean controls were quietly standing as described previously (Colleran et al. 2000,

Published by Bioscientifica Ltd. 
Prisby et al. 2007, Stabley et al. 2013). After completion of the blood flow experiment, animals were killed with Beuthanasia-D Special (approximately $0.6 \mathrm{ml} / \mathrm{kg}$, Schering-Plough Animal Health, Union, NJ, USA) administered via the carotid artery catheter. Hindlimb bones were removed, cleared of muscle and tendon, and divided into regions as described previously (Colleran et al. 2000, Prisby et al. 2007, Dominguez et al. 2010). Individual tissue and reference blood sample radioactivity were determined and individual tissue blood flow $(\mathrm{ml} / \mathrm{min}$ per $100 \mathrm{~g}$ ) was calculated according to the reference sample microsphere method (Ishise et al. 1980). Tissue vascular conductance $(\mathrm{ml} / \mathrm{min}$ per $100 \mathrm{~g} / \mathrm{mmHg})$ was calculated by dividing individual tissue blood flow by mean arterial pressure.

\section{Statistical analyses}

Vascular responses were calculated and expressed as a percentage of vasoconstriction or vasodilation as follows:

Percentage vasoconstriction $=\left(D_{\mathrm{b}}-D_{\mathrm{s}}\right) / D_{\mathrm{b}} \times 100$

Percentage vasodilation $=\left(D_{\mathrm{s}}-D_{\mathrm{b}}\right) /\left(D_{\mathrm{m}}-D_{\mathrm{b}}\right) \times 100$

where $D_{\mathrm{b}}$ was the initial baseline intraluminal diameter measured before experimental intervention, $D_{\mathrm{s}}$ was the steady-state intraluminal diameter measured after agonist addition, and $D_{\mathrm{m}}$ was the maximal diameter recorded at $60 \mathrm{~cm} \mathrm{H}_{2} \mathrm{O}$.

Basal tone was expressed as a percentage of the maximal diameter $\left(D_{\mathrm{m}}\right)$ as follows:

Percentage basal tone $=\left(D_{\mathrm{m}}-D_{\mathrm{b}}\right) / D_{\mathrm{m}} \times 100$

The significance of differences in body mass and bone tissue mass was determined via Student's unpaired $t$-tests. Pressure-response and concentration-response curves were evaluated by using repeated-measures ANOVA with one within (intraluminal pressure or agonist concentration) and one between (experimental groups) factor. Planned contrasts were conducted at each intraluminal pressure or concentration level to determine whether differences existed between experimental groups (lean versus obese). Regression analyses were used to individually investigate the relationship between peak-endotheliumdependent vasodilation and cancellous BMD in the distal femur and total BMD and cortical BMD in the femur diaphysis. Differences in hindlimb bone blood flow and vascular conductance between experimental groups were determined by one-tailed independent-samples $t$-tests. An $\alpha$ level of 0.05 delineated significance.

\section{Results}

\section{Animal and PNA characteristics}

Body mass was greater in obese ZDF rats for the prediabetic, short-term, and long-term diabetic conditions relative to the age-matched lean controls (Table 1). Blood glucose concentration was higher in ZDF rats with shortand long-term diabetes when compared with age-matched lean rats (Table 1), and blood insulin levels were higher in obese ZDF rats under the prediabetic and short-term diabetic conditions (Table 1 ).

Maximal diameter of the femoral PNA did not differ between lean and obese ZDF rats for the prediabetic or short-term diabetic conditions (Table 2). However, maximal diameter of the PNA was smaller in obese ZDF rats with long-term diabetes than that in age-matched lean controls (Table 2). Basal tone of the PNA did not differ between lean and obese ZDF rats at any age studied (Table 2).

\section{PNA vasodilation}

Endothelium-dependent vasodilation of the femoral PNA was greater in prediabetic ZDF rats when compared with age-matched lean ZDF animals (Fig. 1A). This difference was abolished by inhibition of NOS alone and by co-inhibition of NOS and COX (Fig. 1A). There was no difference in endothelium-dependent vasodilation

Table 1 Body mass, blood glucose, insulin concentrations, and femoral bone mineral density (BMD). Values are mean \pm s.E.M.

\begin{tabular}{|c|c|c|c|}
\hline & $\begin{array}{l}7 \text { week } \\
\text { control }\end{array}$ & $\begin{array}{c}7 \text { week } \\
\text { pre-diabetic }\end{array}$ & $\begin{array}{l}13 \text { week } \\
\text { control }\end{array}$ \\
\hline Body mass (g) & $128 \pm 5$ & $174 \pm 6^{a}$ & $276 \pm 8$ \\
\hline Glucose (mg/dl) & $86 \pm 4$ & $104 \pm 8$ & $88 \pm 5$ \\
\hline Insulin (ng/ml) & $1.3 \pm 0.2$ & $4.7 \pm 1.0^{a}$ & $1.2 \pm 0.1$ \\
\hline Total BMD $\left(\mathrm{mg} / \mathrm{cm}^{3}\right)$ & $459 \pm 4$ & $471 \pm 6$ & $562 \pm 7$ \\
\hline Cancellous BMD (mg/cm $\left.{ }^{3}\right)$ & $350 \pm 9$ & $383 \pm 9^{a}$ & $317 \pm 7$ \\
\hline Cortical BMD $\left(\mathrm{mg} / \mathrm{cm}^{3}\right)$ & $1163 \pm 4$ & $1152 \pm 4$ & $1333 \pm 3$ \\
\hline
\end{tabular}

\begin{tabular}{c}
$\begin{array}{c}13 \text { week } \\
\text { short-term }\end{array}$ \\
\hline $341 \pm 14^{a}$ \\
$219 \pm 17^{a}$ \\
$5.2 \pm 1.4^{a}$ \\
$513 \pm 16$ \\
$309 \pm 20$ \\
$1324 \pm 2^{a}$ \\
\hline
\end{tabular}

\begin{tabular}{c}
20 week \\
control \\
\hline $369 \pm 5$ \\
$94 \pm 4$ \\
$1.5 \pm 0.1$ \\
$617 \pm 11$ \\
$326 \pm 10$ \\
$1386 \pm 3$ \\
\hline
\end{tabular}

\begin{tabular}{c}
20 week \\
long-term \\
\hline $402 \pm 13^{a}$ \\
$242 \pm 14^{a}$ \\
$1.6 \pm 0.1$ \\
$487 \pm 7^{a}$ \\
$227 \pm 23^{a}$ \\
$1368 \pm 3^{a}$ \\
\hline
\end{tabular}

${ }^{\text {as }}$ ignificant differences from age-matched lean controls $(P<0.05)$. 
Table 2 Principal nutrient artery (PNA) maximal diameter and basal tone. Values are mean \pm S.E.M.

\begin{tabular}{|c|c|c|}
\hline & $\begin{array}{l}7 \text { week } \\
\text { control }\end{array}$ & $\begin{array}{c}7 \text { week } \\
\text { pre-diabetic }\end{array}$ \\
\hline $\begin{array}{l}\text { PNA maximal diameter }(\mu \mathrm{m}) \\
\text { PNA basal tone }(\%)\end{array}$ & $\begin{array}{r}164 \pm 3 \\
50 \pm 4\end{array}$ & $\begin{array}{r}165 \pm 3 \\
44 \pm 5\end{array}$ \\
\hline
\end{tabular}

${ }^{\text {a }}$ Significant differences from age-matched lean controls $(P<0.05)$.

between short-term diabetic animals and lean control ZDF rats (Fig. 1B). Endothelium-dependent vasodilation of the PNA in ZDF rats with long-term diabetes was lower than that of lean controls (Fig. 1C), and this difference was abolished by NOS inhibition alone and in combination with COX inhibition.

Endothelium-independent vasodilation in response to SNP did not differ between lean ZDF rats and obese ZDF animals for the prediabetic and short-term diabetic conditions (Fig. 2). However, SNP-mediated vasodilation was attenuated in PNAs from long-term obese ZDF rats relative to lean controls (Fig. 2).

\section{PNA vasoconstriction}

Vasoconstrictor responsiveness to $\mathrm{KCl}$ was greater in prediabetic animals relative to lean ZDF rats (Supplementary Figure 1, see section on supplementary data given at the end of this article). However, there were no differences in vasoconstrictor responses to $\mathrm{KCl}$ in PNAs from animals with short-term or long-term diabetes.

NE-induced vasoconstriction of the PNA was not different in animals with prediabetes or short-term diabetes relative to age-matched lean controls (Supplementary Figure 2, see section on supplementary data given at the end of this article). However, NE-induced vasoconstriction was greater in animals with long-term diabetes at concentrations between $10^{-7}$ and $10^{-6} \mathrm{M}$ (Fig. 3A). When the PNAs were denuded of the endothelium, differences in NE-mediated vasoconstriction between obese and lean ZDF rats were abolished (Fig. 3B).

Active myogenic and passive pressure-diameter responses were not different between animals with prediabetes or short-term diabetes and their lean counterparts (Supplementary Figure 3, see section on supplementary data given at the end of this article). However, active myogenic vasoconstriction was greater in animals with long-term diabetes relative to lean control rats (Fig. 4A), and the passive pressure-diameter responses were lower in long-term diabetic rats compared with lean controls (Fig. 4B).

\section{Femoral BMD}

Total and cortical BMD were the same in prediabetic rats versus lean controls, whereas cancellous BMD of the distal femur was greater for the prediabetic condition (Table 1). For animals with short-term diabetes, total and cancellous BMD were not different between obese and lean ZDF rats, while cortical BMD was lower in obese ZDF rats (Table 1). Rats in both of these age groups still exhibit skeletal growth, therefore the effects of factors present in the prediabetic and short-term diabetic states may occur as a result of skeletal growth. In long-term obese ZDF rats, where the animals are more skeletally mature, total, cancellous, and cortical BMD were lower than that in lean ZDF animals (Table 1).

\section{Relationship between endothelium-dependent vasodilation and femoral BMD}

Cancellous BMD of the femur was positively associated with peak endothelium-dependent vasodilation of the PNA during prediabetes, short-term diabetes, and longterm diabetes (Fig. 5A, B and C). In addition, endotheliumdependent vasodilation was positively correlated with total BMD (Fig. 6A) and cortical BMD (Fig. 6B) of the femur for animals with long-term diabetes.

\section{Blood flow, arterial pressure, and vascular conductance}

Blood flow was lower in all regions of the femur (Fig. 7A) and in all other skeletal regions of the hindlimb (Supplementary Figure 4, see section on supplementary data given at the end of this article) in 20-week-old ZDF rats with long-term diabetes. Mean arterial pressure was not different between ZDF rats with long-term diabetes $(160 \pm 6 \mathrm{mmHg})$ and lean controls $(160 \pm 4 \mathrm{mmHg})$. Consequently, vascular conductance was lower in the femur (Fig. 7B) and all regions of the hindlimb skeleton of 20-week-old obese ZDF rats with long-term diabetes (Supplementary Tables 1 and 2, see section on supplementary data given at the end of this article).

Published by Bioscientifica Ltd. 

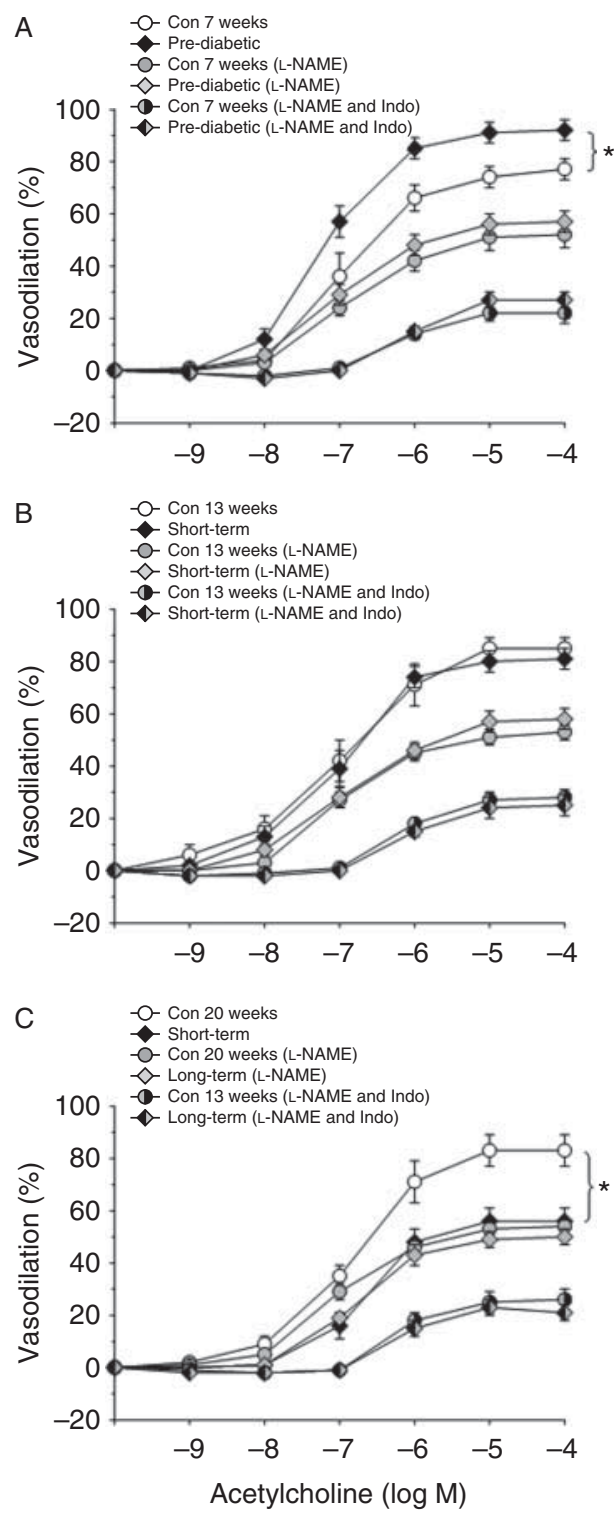

Figure 1

Effects of prediabetes (A), short-term diabetes (B), and long-term diabetes (C) on endothelium-dependent vasodilation of the femoral principal nutrient artery alone, in the presence of the nitric oxide synthase inhibitor L-NAME, and in the presence of L-NAME and the cyclooxygenase inhibitor indomethacin (Indo). Values are means \pm s.E.M., $n=14-15$ /group. * Mean is different from that for age-matched nondiabetic control animals $(P<0.05)$.

\section{Discussion}

Previous work has shown a deterioration of both bone health and general cardiovascular function during the progression of T2DM (Grundy et al. 1999, Prisby et al. 2008, Leslie et al. 2012). However, little is known regarding the effects of T2DM on the bone circulation. Thus, the primary purpose of this study was to determine whether the progression of T2DM through a prediabetic, shortterm diabetic, and more chronic diabetic state alters mechanisms of vascular control in bone resistance arteries. The results indicate few adverse effects of the prediabetic and short-term diabetic conditions on the vasodilator or vasoconstrictor properties of the femoral PNA. However, with long-term diabetes the PNA shifts toward a more pro-vasoconstrictor phenotype. This is evidenced by a decrement in endothelium-dependent (Fig. 1C) and -independent (Fig. 2) vasodilation, an enhanced noradrenergic (Fig. 3A) and myogenic (Fig. 4A) vasoconstrictor responsiveness, as well as a decrease in the passive mechanical distensibility (Fig. 4B) of the PNA. Consequently, a secondary purpose of this study was to determine whether this shift toward a more pro-vasoconstrictor phenotype in the bone resistance vasculature diminishes bone and marrow perfusion and vascular conductance in vivo. The results indicate an impairment of bone and marrow blood flow (Fig. 7A) and vascular conductance (Fig. 7B) with long-term T2DM. Given the potential coupling of bone vascular signaling and blood flow with skeletal remodeling (Parfitt 2000, Farhat \& Cauley 2008, Lampropoulos et al. 2012, Prisby et al. 2012), the present results indicate that the profound impairment of the bone circulation could contribute to the osteopenia found to occur in long bones with chronic T2DM.

T2DM is a physiologically devastating disease whose deleterious effects on bone and the cardiovascular system are multifaceted. For example, the hyperglycemia and hyperlipidemia associated with T2DM can stimulate mitochondrial free radical production and alter redox balance to promote endothelial dysfunction in the

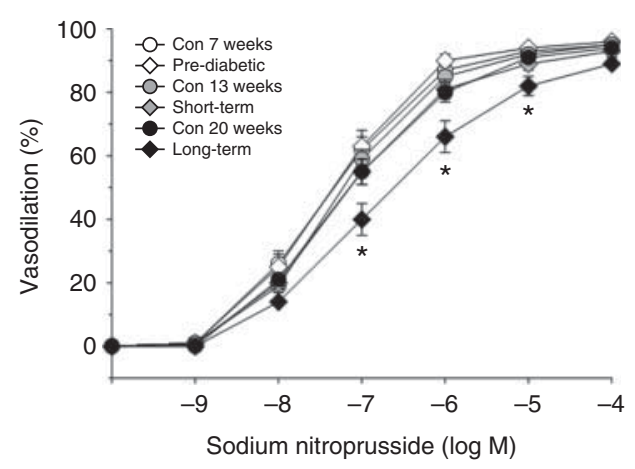

Figure 2

Effects of prediabetes, short-term diabetes, and long-term diabetes on sodium nitroprusside-induced vasodilation of the femoral principal nutrient artery (PNA). Values are means \pm s.E.M., $n=8-10 /$ group. *Mean PNA response of 20-week-old obese ZDF rats is different from that of 20-week-old lean ZDF rats $(P<0.05)$.

Published by Bioscientifica Ltd. 

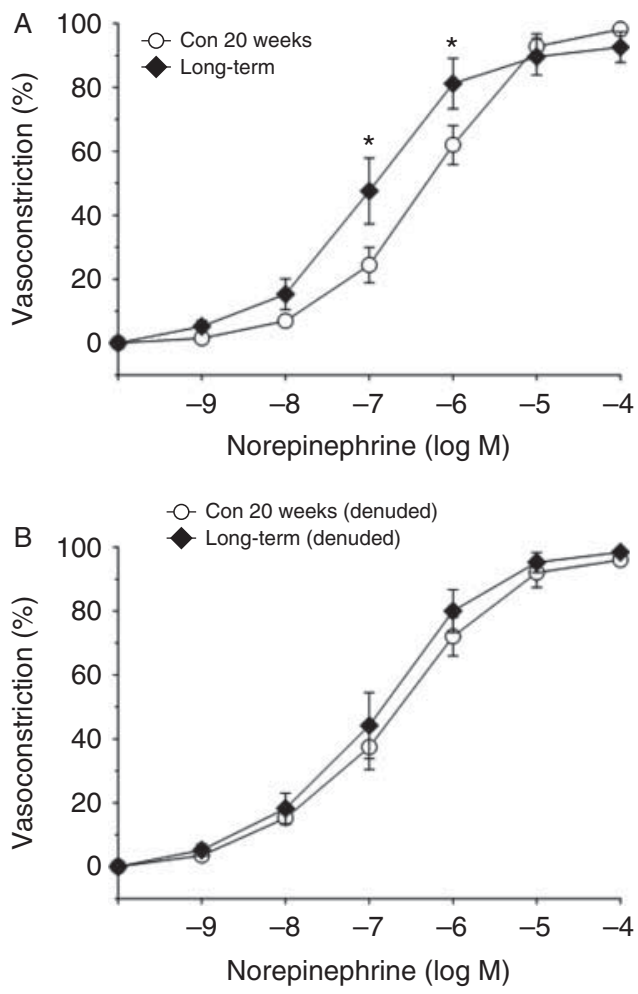

Figure 3

Effects of long-term diabetes on norepinephrine-induced vasoconstriction of the femoral principal nutrient artery (PNA) with the endothelium intact (A) and with the endothelium removed (B). Values are means \pm s.E.M., $n=10-14$ /group. *Mean PNA response of 20-week-old obese ZDF rats is different from that of 20 -week-old lean ZDF rats $(P<0.05)$.

vasculature (Schalkwijk \& Stehouwer 2005, van den Oever et al. 2010). Impaired endothelium-dependent vasodilation of conduit arteries is present in adolescents (Naylor et al. 2011) and adults (Hogikyan et al. 1998, Makimattila et al. 1999, Bruno et al. 2012, Kotb et al. 2012) with T2DM, and has been shown to be associated with elevated oxidative stress and the uncoupling of endothelial NOS (Pannirselvam et al. 2002), resulting in diminished bioavailability of NO to induce vascular smooth muscle cell relaxation. Although T2DM-induced decreases in conduit artery endothelium-dependent vasodilation (Makimattila et al. 1999, Rossi et al. 2005) do not necessarily reflect changes in the microvasculature (Meyer et al. 2008), results from this study also demonstrate endothelial dysfunction in the bone microcirculation in T2DM (Fig. 1C). Furthermore, the results indicate that this is due to an impairment of endothelial NO signaling, as indicated by the elimination of differences in endothelium-dependent vasodilation between PNAs from obese ZDF rats and agematched lean controls when NOS inhibition is present.
The enhanced adrenergic vasoconstriction of the femur resistance vasculature detected in the present study (Fig. 3A) coincides with observations of greater adrenergic vasoconstriction in the forearms of humans with T2DM (Hogikyan et al. 1999). Such changes in vasoconstrictor responsiveness could be mediated through the $\alpha$-adrenergic receptor signaling pathway in smooth muscle cells that elicit vasoconstriction, or the modulatory influence of $\alpha$-adrenergic receptor signaling in endothelial cells that promote vasodilation. Results for bone resistance arteries indicate the latter effect, because removal of the endothelium abolished differences in PNA responses to NE (Fig. 3B). Results of previous research with skeletal muscle resistance arteries have indicated a similar endothelium-dependent effect on NE-mediated vasoconstriction with long-term diabetes (Lesniewski et al. 2008). Together, the results of endothelium-dependent vasodilation and NE-mediated vasoconstriction are indicative of a critical role for the
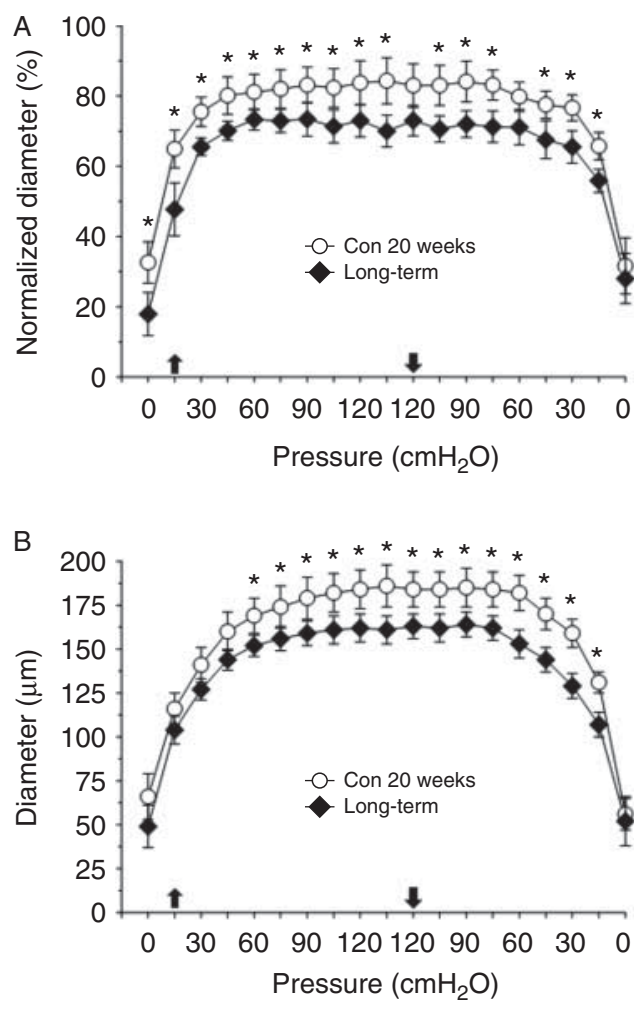

Figure 4

Effects of long-term diabetes on active myogenic vasoconstriction $(A)$ and the passive pressure-diameter relation (B) of the femoral principal nutrient artery. Upwards-pointing arrows indicate where pressure began to be increased; downward-pointing arrows indicate where pressure began to be lowered. Values are means \pm s.E.M., $n=13-14$ /group. *Mean PNA response of 20-week-old obese ZDF rats is different from that of 20-week-old lean ZDF rats $(P<0.05)$.

Published by Bioscientifica Ltd 

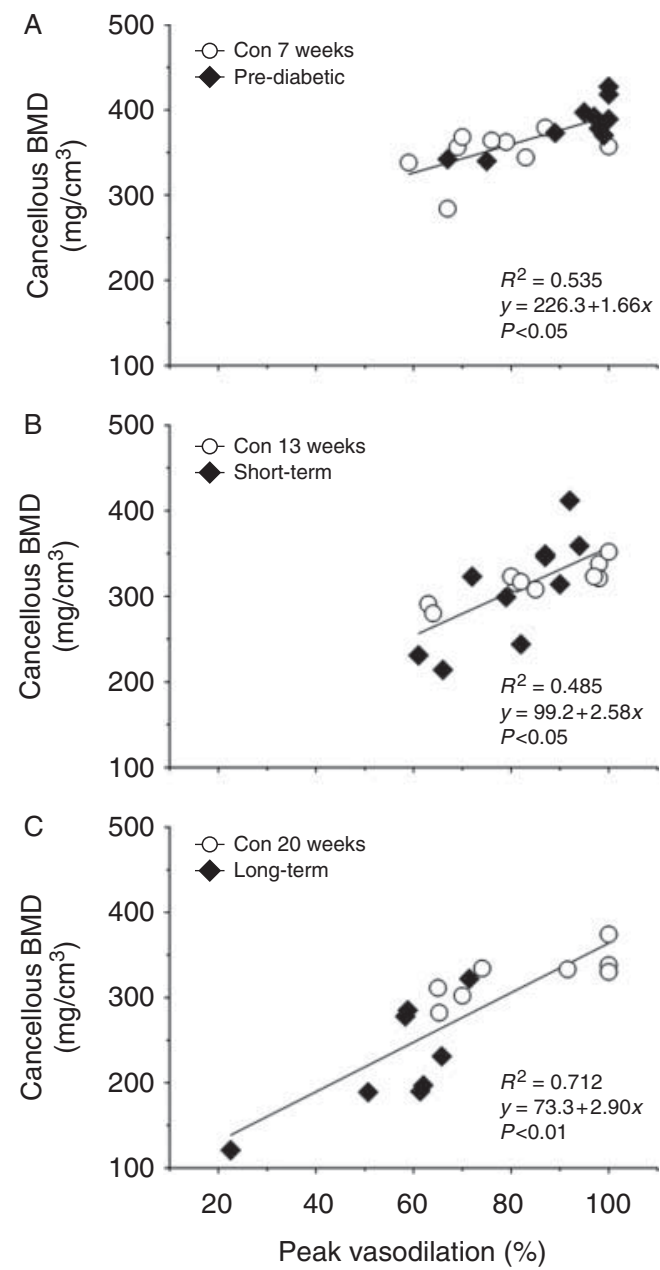

Figure 5

Scattergrams showing the relationship between cancellous bone mineral density (BMD) in the distal femur and peak endothelium-dependent vasodilation of the femoral PNA of lean and obese ZDF rats during prediabetes (A), short-term diabetes (B), and long-term diabetes (C). A significant linear relationship $(P<0.05)$ exists between cancellous BMD and peak PNA vasodilation for each condition.

endothelium in the transition of the bone resistance arteries to a more pro-vasoconstrictor phenotype with T2DM.

However, alterations in the bone resistance vasculature with T2DM are not limited to changes in endothelial cell signaling. Endothelium-independent vasodilation to SNP is impaired (Fig. 2), active myogenic vasoconstriction is enhanced (Fig. 4A), and the passive distensibility of the PNA is decreased with long-term diabetes (Fig. 4B). Each of these changes would also contribute to greater vasoconstrictor responsiveness, which correspond to reductions in vascular conductance in vivo (Fig. 7B).

The decrements in SNP-mediated vasodilation (Fig. 2) of the PNA indicates stiffer bone arteries are associated with long-term diabetes. One potential mechanism for increased stiffness is an increase in vascular calcification. Results of previous work have indicated that there is an increased risk of arterial calcification in T2DM (Kreines et al. 1985), and that vascular calcification in diabetes is associated with decreased muscle blood flow (Christensen 1968). Results from several studies also indicate positive associations between vascular calcification and osteoporosis or low BMD (Hak et al. 2000, Reddy et al. 2008, Adragao et al. 2009, Choi et al. 2009, Hyder et al. 2009, Bandeira et al. 2012). In particular, iliac artery vascular calcification is positively associated with lumbar spine and femoral neck osteoporosis in men with T2DM (Bandeira et al. 2012).

The association between vascular alterations and bone loss are probably affected by other factors beyond changes in arterial calcification. Evidence indicates an active role of the vasculature in coupling vascular signaling and bone remodeling (Colleran et al. 2000, Dominguez et al. 2010, Prisby et al. 2012). For instance, the basic multicellular unit (BMU) that drives bone remodeling activity may be
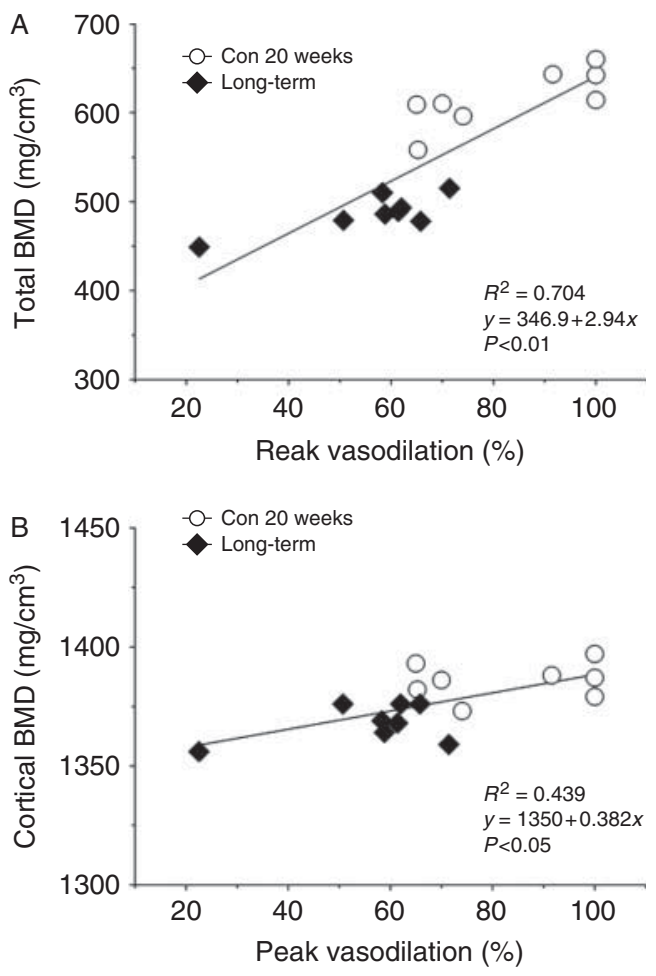

Figure 6

Scattergrams showing the relationship between total bone mineral density (BMD) of the distal femur (A) and cortical BMD of the femoral mid-shaft (B) with peak endothelium-dependent vasodilation of the femoral PNA for lean and obese ZDF rats with long-term diabetes. A significant linear relationship $(P<0.05)$ exists between total and cortical BMD and peak PNA vasodilation.

Published by Bioscientifica Ltd. 

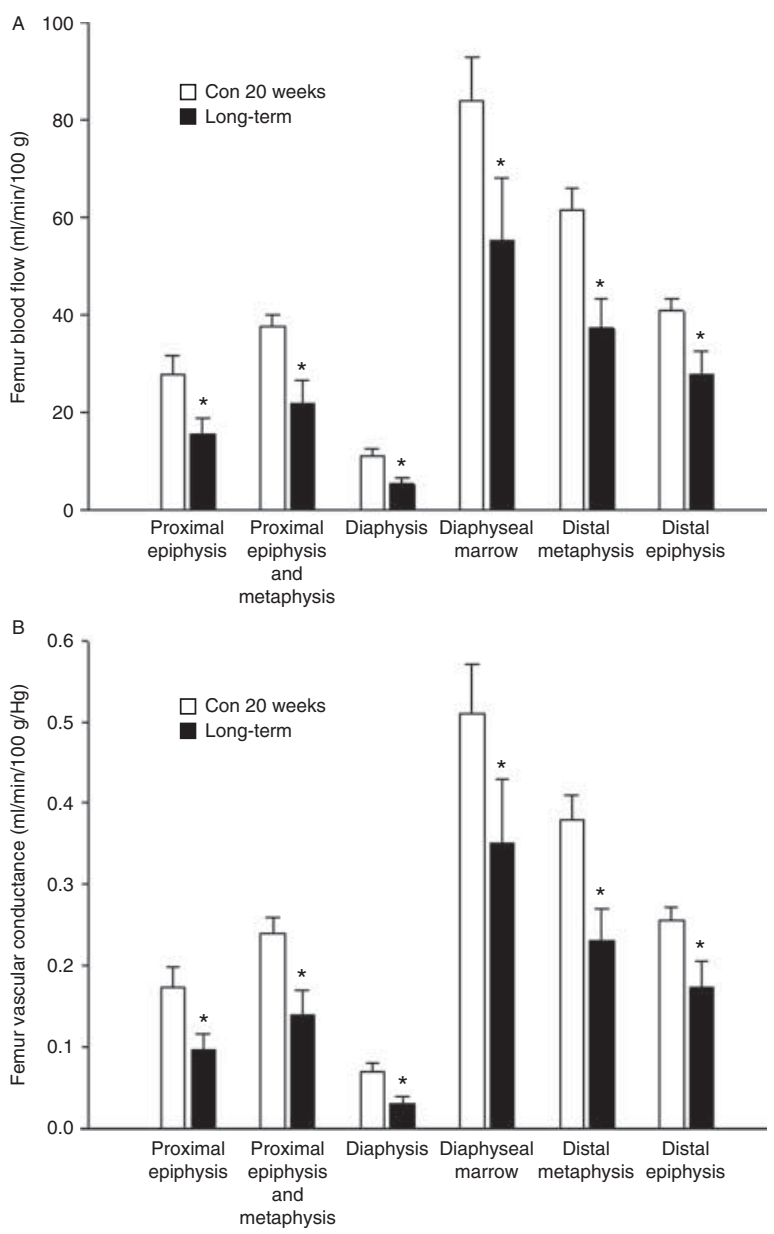

potent inhibitor of osteoclast-driven bone resorption (MacIntyre et al. 1991) and has a positive effect on osteoblastic differentiation (Hikiji et al. 1997), while $\mathrm{PGI}_{2}$ has been shown to be a powerful inhibitor of osteoclastic bone resorption (Chambers \& Ali 1983) and $\mathrm{PGE}_{2}$ has been reported to increase osteoblast and decrease osteoclast numbers (Jee et al. 1987). Results from this study indicate that NO signaling from the vasculature is the more important molecule in the apparent coupling of endothelium-dependent vasodilation to $\mathrm{BMD}$, given that differences in endothelium-dependent vasodilation in PNAs from obese and lean ZDF rats were abolished by NOS inhibition alone (Fig. 1A and C).

An additional factor affecting the relationship between the vasculature and bone health is bone perfusion. Bone blood flow facilitates the generation of differences in hydrostatic pressure between the medullary cavity and bone capillary efferents that drive centrifugal interstitial fluid flow (Montgomery et al. 1988). The resultant transcortical fluid flow stimulates osteocytes and osteoblasts (Knothe Tate 2003) and subsequent bone formation (Turner 1999, Riddle \& Donahue 2009). Thus, the decreases in bone and marrow blood flow found in this study (Fig. 7A) could also compromise important flow and pressure stimuli that affect bone formation.

The selection of an animal model of T2DM is important because no single model will permit the investigation of all disease-related questions (Peterson et al. 1990). For example, the Goto-Kakizaki rat is a valuable model for investigating the effects of T2DM in the absence of a corresponding increase in adiposity (Akash et al. 2013). Therein, the model fails to replicate the typical clinical T2DM phenotype that includes obesity. The Zucker obese rat is a valuable model of the metabolic syndrome (Kurtz et al. 1989) with impaired glucose tolerance and insulin resistance, but it fails to demonstrate hyperglycemia (Peterson et al. 1990). The ZDF rat used in this study was originally derived from the Zucker obese rat strain via selection and inbreeding of animals that spontaneously demonstrated unusually high blood glucose levels (Peterson et al. 1990). The ZDF rat displays a well-defined T2DM disease progression (Kawaguchi et al. 1999, Etgen \& Oldham 2000) with deleterious changes in obesity and blood lipid profiles (Leonard et al. 2005) that correspond with human T2DM. As glucose and insulin levels have important effects on bone health (Inzerillo \& Epstein 2004) and resistance artery function (Lesniewski et al. 2008), this study was designed to leverage known changes in ZDF rat T2DM disease progression to investigate their effects on potential bone-vascular interactions. 
In conclusion, the results of this study indicate that few vasomotor alterations occur in the bone resistance vasculature in the prediabetic and short-term diabetic states. However, the femoral PNA shifts toward a more pro-vasoconstrictor phenotype with long-term diabetes, as indicated by decreases in endothelium-dependent (Fig. 1C) and -independent (Fig. 2) vasodilation, enhanced noradrenergic (Fig. 3A) and myogenic (Fig. 4A) vasoconstrictor responsiveness, and a decrease in the passive mechanical distensibility (Fig. 4B). The enhanced vasoconstrictor responsiveness of the bone resistance vasculature was evident in vivo from decreases in bone and marrow blood flow (Fig. 7A) and vascular conductance (Fig. 7B) with long-term T2DM. Given the potential coupling of bone vascular signaling molecules (Figs 5 and 6) and bone fluid dynamics with skeletal remodeling (Parfitt 2000, Farhat \& Cauley 2008, Lampropoulos et al. 2012, Prisby et al. 2012), the present results indicate that the impairment of the bone circulation could contribute to the bone loss found to occur during the progression of T2DM.

\section{Supplementary data}

This is linked to the online version of the paper at http://dx.doi.org/10.1530/ JOE-14-0514.

\section{Declaration of interest}

The authors declare that there is no conflict of interest that could be perceived as prejudicing the impartiality of the research reported.

\section{Funding}

This study was supported by grants from the National Aeronautics and Space Administration (NNX12AL41G and NNX14AQ57G) and National Institutes of Health (AG-31317).

\section{Author contribution statement}

The authors have made the following declarations about their contributions: J N S, R D P, and M D D designed the study. J N S, R D P, and B J B conducted the study. J N S, R D $P$, and $B J B$ were involved in data collection. J N S, R D P, and M D D carried out data analysis. J N S, R D P, B J B, and M D D were involved in data interpretation. J N S and M D D helped in drafting the manuscript. J N S, R D P, B J B, and M D D revised manuscript content. J N S, $R D P, B J B$, and $M D D$ helped in approving the final version of the manuscript. M D D takes responsibility for the integrity of the data analysis.

\section{References}

Adragao T, Herberth J, Monier-Faugere MC, Branscum AJ, Ferreira A, Frazao JM, Dias Curto J \& Malluche HH 2009 Low bone volume - a risk factor for coronary calcifications in hemodialysis patients. Clinical
Journal of the American Society of Nephrology 4 450-455. (doi:10.2215/ CJN.01870408)

Akash MS, Rehman K \& Chen S 2013 Goto-Kakizaki rats: its suitability as non-obese diabetic animal model for spontaneous type 2 diabetes mellitus. Current Diabetes Reviews 9 387-396. (doi:10.2174/ 15733998113099990069)

Bandeira E, Neves AP, Costa C \& Bandeira F 2012 Association between vascular calcification and osteoporosis in men with type 2 diabetes. Journal of Clinical Densitometry 15 55-60. (doi:10.1016/j.jocd.2011. 07.002)

Bridgeman G \& Brookes M 1996 Blood supply to the human femoral diaphysis in youth and senescence. Journal of Anatomy 188 611-621.

Bruno RM, Penno G, Daniele G, Pucci L, Lucchesi D, Stea F, Landini L, Cartoni G, Taddei S, Ghiadoni L et al. 2012 Type 2 diabetes mellitus worsens arterial stiffness in hypertensive patients through endothelial dysfunction. Diabetologia 55 1847-1855. (doi:10.1007/s00125-0122517-1)

Chambers TJ \& Ali NN 1983 Inhibition of osteoclastic motility by prostaglandins $\mathrm{I}_{2}, \mathrm{E}_{1}, \mathrm{E}_{2}$ and 6-oxo- $\mathrm{E}_{1}$. Journal of Pathology 139 383-397. (doi:10.1002/path.1711390313)

Choi SH, An JH, Lim S, Koo BK, Park SE, Chang HJ, Choi SI, Park YJ, Park KS, Jang HC et al. 2009 Lower bone mineral density is associated with higher coronary calcification and coronary plaque burdens by multidetector row coronary computed tomography in pre and postmenopausal women. Clinical Endocrinology 71 644-651. (doi:10.1111/j.13652265.2009.03535.x)

Christensen NJ 1968 Muscle blood flow, measured by xenon ${ }^{133}$ and vascular calcifications in diabetics. Acta Medica Scandinavica 183 449-454. (doi:10.1111/j.0954-6820.1968.tb10506.x)

Colleran PN, Wilkerson MK, Bloomfield SA, Suva LJ, Turner RT \& Delp MD 2000 Alterations in skeletal perfusion with simulated microgravity: a possible mechanism for bone remodeling. Journal of Applied Physiology 89 1046-1054.

Delp MD 1999 Myogenic and vasoconstrictor responsiveness of skeletal muscle arterioles is diminished by hindlimb unloading. Journal of Applied Physiology 86 1178-1184.

Delp MD \& Armstrong RB 1988 Blood flow in normal and denervated muscle during exercise in conscious rats. American Journal of Physiology 255 H1509-H1515.

Dominguez JM II, Prisby RD, Muller-Delp JM, Allen MR \& Delp MD 2010 Increased nitric oxide-mediated vasodilation of bone resistance arteries is associated with increased trabecular bone volume after endurance training in rats. Bone $\mathbf{4 6}$ 813-819. (doi:10.1016/j.bone.2009.10.029)

Donato AJ, Lesniewski LA \& Delp MD 2005 The effects of aging and exercise training on endothelin-1 vasoconstrictor responses in rat skeletal muscle arterioles. Cardiovascular Research 66 393-401. (doi:10.1016/j. cardiores.2004.10.023)

Etgen GJ \& Oldham BA 2000 Profiling of Zucker diabetic fatty rats in their progression to the overt diabetic state. Metabolism: Clinical and Experimental 49 684-688. (doi:10.1016/S0026-0495(00)80049-9)

Farhat GN \& Cauley JA 2008 The link between osteoporosis and cardiovascular disease. Clinical Cases in Mineral and Bone Metabolism 5 19-34.

Flaim SF \& Zelis RF 1980 Regional distribution of cardiac output in conscious rats at rest and during exercise. Effects of diltiazem. Chest 78 187-192.

Grundy SM, Benjamin IJ, Burke GL, Chait A, Eckel RH, Howard BV, Mitch W, Smith SC Jr \& Sowers JR 1999 Diabetes and cardiovascular disease: a statement for healthcare professional from the American Heart Association. Circulation 100 1134-1146. (doi:10.1161/01.CIR.100.10.1134)

Hak AE, Pols HA, van Hemert AM, Hofman A \& Witteman JC 2000 Progression of aortic calcification is associated with metacarpal bone loss during menopause: a population-based longitudinal study. Arteriosclerosis, Thrombosis, and Vascular Biology 20 1926-1931. (doi:10.1161/01.ATV.20.8.1926)

Hikiji H, Shin WS, Oida S, Takato T, Koizumi T \& Toyo-oka T 1997 Direct action of nitric oxide on osteoblastic differentiation. FEBS Letters $\mathbf{4 1 0}$ 238-242. (doi:10.1016/S0014-5793(97)00597-8) 
Hogikyan RV, Galecki AT, Pitt B, Halter JB, Greene DA \& Supiano MA 1998 Specific impairment of endothelium-dependent vasodilation in subjects with type 2 diabetes independent of obesity. Journal of Clinical Endocrinology and Metabolism 83 1946-1952. (doi:10.1210/jcem.83.6. 4907)

Hogikyan RV, Galecki AT, Halter JB \& Supiano MA 1999 Heightened norepinephrine-mediated vasoconstriction in type 2 diabetes. Metabolism: Clinical and Experimental 48 1536-1541. (doi:10.1016/ S0026-0495(99)90242-1)

Hyder JA, Allison MA, Wong N, Papa A, Lang TF, Sirlin C, Gapstur SM, Ouyang P, Carr JJ \& Criqui MH 2009 Association of coronary artery and aortic calcium with lumbar bone density: the MESA abdominal aortic calcium study. American Journal of Epidemiology 169 186-194. (doi:10.1093/aje/kwn303)

Inzerillo AM \& Epstein S 2004 Osteoporosis and diabetes mellitus. Reviews in Endocrine \& Metabolic Disorders 5 261-268. (doi:10.1023/B:REMD. 0000032415.83124.20)

Ishise S, Pegram BL, Yamamoto J, Kitamura Y \& Frohlich ED 1980 Reference sample microsphere method: cardiac output and blood flows in conscious rat. American Journal of Physiology 239 H443-H449.

Jee WS, Ueno K, Kimmel DB, Woodbury DM, Price P \& Woodbury LA 1987 The role of bone cells in increasing metaphyseal hard tissue in rapidly growing rats treated with prostaglandin $\mathrm{E}_{2}$. Bone $\mathbf{8} 171-178$. (doi:10.1016/8756-3282(87)90017-2)

Kawaguchi M, Koshimura K, Murakami Y, Tsumori M, Gonda T \& Kato Y 1999 Antihypertensive effect of insulin via nitric oxide production in the Zucker diabetic fatty rat, an animal model for non-insulindependent diabetes mellitus. European Journal of Endocrinology 140 341-349. (doi:10.1530/eje.0.1400341)

Knothe Tate ML 2003 "Whither flows the fluid in bone?" an osteocyte's perspective Journal of Biomechanics 36 1409-1424. (doi:10.1016/S00219290(03)00123-4)

Kotb NA, Gaber R, Salah W \& Elhendy A 2012 Relations among glycemic control, circulating endothelial cells, nitric oxide, and flow mediated dilation in patients with type 2 diabetes mellitus. Experimental and Clinical Endocrinology \& Diabetes 120 460-465. (doi:10.1055/s-0032-1306349)

Kreines K, Johnson E, Albrink M, Knatterud GL, Levin ME, Lewitan A, Newberry W \& Rose FA 1985 The course of peripheral vascular disease in non-insulin-dependent diabetes. Diabetes Care 8 235-243. (doi:10.2337/diacare.8.3.235)

Kurtz TW, Morris RC \& Pershadsingh HA 1989 The Zucker fatty rat as a genetic model of obesity and hypertension. Hypertension 13 896-901. (doi:10.1161/01.HYP.13.6.896)

Lampropoulos CE, Papaioannou I \& D'Cruz DP 2012 Osteoporosis - a risk factor for cardiovascular disease? Nature Reviews. Rheumatology $\mathbf{8}$ 587-598. (doi:10.1038/nrrheum.2012.120)

Leonard BL, Watson RN, Loomes KM, Phillips AR \& Cooper GJ 2005 Insulin resistance in the Zucker diabetic fatty rat: a metabolic characterisation of obese and lean phenotypes. Acta Diabetologica 42 162-170. (doi:10.1007/s00592-005-0197-8)

Leslie WD, Rubin MR, Schwartz AV \& Kanis JA 2012 Type 2 diabetes and bone. Journal of Bone and Mineral Research 27 2231-2237. (doi:10.1002/ jbmr.1759)

Lesniewski LA, Donato AJ, Behnke BJ, Woodman CR, Laughlin MH, Ray CA \& Delp MD 2008 Decreased NO signaling leads to enhanced vasoconstrictor responsiveness in skeletal muscle arterioles of the ZDF rat prior to overt diabetes and hypertension. American Journal of Physiology. Heart and Circulatory Physiology 294 H1840-H1850. (doi:10.1152/ajpheart.00692.2007)

MacIntyre I, Zaidi M, Alam AS, Datta HK, Moonga BS, Lidbury PS, Hecker M \& Vane JR 1991 Osteoclastic inhibition: an action of nitric oxide not mediated by cyclic GMP. PNAS 88 2936-2940. (doi:10.1073/pnas.88.7. 2936)

Makimattila S, Liu ML, Vakkilainen J, Schlenzka A, Lahdenpera S, Syvanne M, Mantysaari M, Summanen P, Bergholm R, Taskinen MR et al. 1999 Impaired endothelium-dependent vasodilation in type 2 diabetes. Relation to LDL size, oxidized LDL, and antioxidants. Diabetes Care 22 973-981. (doi:10.2337/diacare.22.6.973)

Meininger GA, Harris PD \& Joshua IG 1984 Distributions of microvascular pressure in skeletal muscle of one-kidney, one clip, two-kidney, one clip, and deoxycorticosterone-salt hypertensive rats. Hypertension $\mathbf{6}$ 27-34. (doi:10.1161/01.HYP.6.1.27)

Melton LJ III, Leibson CL, Achenbach SJ, Therneau TM \& Khosla S 2008 Fracture risk in type 2 diabetes: update of a population-based study. Journal of Bone and Mineral Research 23 1334-1342. (doi:10.1359/jbmr. 080323)

Meyer MF, Lieps D, Schatz H \& Pfohl M 2008 Impaired flow-mediated vasodilation in type 2 diabetes: lack of relation to microvascular dysfunction. Microvascular Research 76 61-65. (doi:10.1016/j.mvr.2008. 03.001)

Montgomery RJ, Sutker BD, Bronk JT, Smith SR \& Kelly PJ 1988 Interstitial fluid flow in cortical bone. Microvascular Research 35 295-307. (doi:10.1016/0026-2862(88)90084-2)

Muller-Delp JM, Spier SA, Ramsey MW \& Delp MD 2002 Aging impairs endothelium-dependent vasodilation in rat skeletal muscle arterioles. American Journal of Physiology. Heart and Circulatory Physiology 283 H1662-H1672. (doi:10.1152/ajpheart.00004.2002)

Naylor LH, Green DJ, Jones TW, Kalic RJ, Suriano KL, Shah M, Hopkins N \& Davis EA 2011 Endothelial function and carotid intima-medial thickness in adolescents with type 2 diabetes mellitus. Journal of Pediatrics 159 971-974. (doi:10.1016/j.jpeds.2011.05.019)

Pannirselvam M, Verma S, Anderson TJ \& Triggle CR 2002 Cellular basis of endothelial dysfunction in small mesenteric arteries from spontaneously diabetic $(\mathrm{db} / \mathrm{db}-/-)$ mice: role of decreased tetrahydrobiopterin bioavailability. British Journal of Pharmacology 136 255-263. (doi:10.1038/sj.bjp.0704683)

Parfitt AM 2000 The mechanism of coupling: a role for the vasculature. Bone 26 319-323. (doi:10.1016/S8756-3282(00)80937-0)

Pead MJ \& Lanyon LE 1989 Indomethacin modulation of load-related stimulation of new bone formation in vivo. Calcified Tissue International 45 34-40. (doi:10.1007/BF02556658)

Peterson RG, Shaw WN, Neel M, Little LA \& Eichberg J 1990 Zucker diabetic fatty rat as a model for non-insulin-dependent diabetes mellitus. ILAR Journal 32 16-19. (doi:10.1093/ilar.32.3.16)

Prisby RD, Ramsey MW, Behnke BJ, Dominguez JM II, Donato AJ, Allen MR \& Delp MD 2007 Aging reduces skeletal blood flow, endotheliumdependent vasodilation, and NO bioavailability in rats. Journal of Bone and Mineral Research 22 1280-1288. (doi:10.1359/jbmr.070415)

Prisby RD, Swift JM, Bloomfield SA, Hogan HA \& Delp MD 2008 Altered bone mass, geometry and mechanical properties during the development and progression of type 2 diabetes in the Zucker diabetic fatty rat. Journal of Endocrinology 199 379-388. (doi:10.1677/JOE-08-0046)

Prisby RD, Dominguez JM II, Muller-Delp J, Allen MR \& Delp MD 2012 Aging and estrogen status: a possible endothelium-dependent vascular coupling mechanism in bone remodeling. PLoS ONE 7 e48564. (doi:10.1371/journal.pone.0048564)

Reddy J, Bilezikian JP, Smith SJ \& Mosca L 2008 Reduced bone mineral density is associated with breast arterial calcification. Journal of Clinical Endocrinology and Metabolism 93 208-211. (doi:10.1210/jc.2007-0693)

Riddle RC \& Donahue HJ 2009 From streaming-potentials to shear stress: 25 years of bone cell mechanotransduction. Journal of Orthopaedic Research 27 143-149. (doi:10.1002/jor.20723)

Rossi R, Cioni E, Nuzzo A, Origliani G \& Modena MG 2005 Endothelialdependent vasodilation and incidence of type 2 diabetes in a population of healthy postmenopausal women. Diabetes Care $\mathbf{2 8}$ 702-707. (doi:10.2337/diacare.28.3.702)

Schalkwijk CG \& Stehouwer CD 2005 Vascular complications in diabetes mellitus: the role of endothelial dysfunction. Clinical Science 109 143-159. (doi:10.1042/CS20050025)

Schwartz AV 2003 Diabetes mellitus: does it affect bone? Calcified Tissue International 73 515-519. (doi:10.1007/s00223-003-0023-7) 
Stabley JN, Prisby RD, Behnke BJ \& Delp MD 2013 Chronic skeletal unloading of the rat femur: mechanisms and functional consequences of vascular remodeling. Bone 57 355-360. (doi:10.1016/j.bone.2013.09.003)

Truett GE, Bahary N, Friedman JM \& Leibel RL 1991 Rat obesity gene fatty ( $f a)$ maps to chromosome 5: evidence for homology with the mouse gene diabetes $(d b)$. PNAS $\mathbf{8 8} 7806-7809$. (doi:10.1073/pnas.88.17.7806)

Turner CH 1999 Site-specific skeletal effects of exercise: importance of interstitial fluid pressure. Bone 24 161-162. (doi:10.1016/S87563282(98)00184-7) van den Oever IA, Raterman HG, Nurmohamed MT \& Simsek S 2010 Endothelial dysfunction, inflammation, and apoptosis in diabetes mellitus. Mediators of Inflammation 2010 792393. (doi:10.1155/2010/ 792393)

van de Ree MA, Huisman MV, de Man FH, van der Vijver JC, Meinders AE \& Blauw GJ 2001 Impaired endothelium-dependent vasodilation in type 2 diabetes mellitus and the lack of effect of simvastatin. Cardiovascular Research 52 299-305. (doi:10.1016/S00086363(01)00379-0)

Received in final form 7 January 2015

Accepted 4 February 2015
Published by Bioscientifica Ltd. 